\title{
PESQUISA INTERVENTIVA E FORMAÇÃO PROFISSIONAL: EXPERIÊNCIAS DESENVOLVIDAS NOS CURSOS DE EDUCAÇÃO FÍSICA DA UFG/REJ/BRASIL ${ }^{1}$
}

\author{
RENATA MACHADO DE ASSIS \\ Doutora em Educação Física pela Universidade Federal de Góis. Mestre em Educação pela \\ Universidade Federal de Minas Gerais. Docente dos cursos de Educação Física e do Programa de Pós- \\ Graduação em Educação da UFG/Regional Jataí. E-mail: renatafef@ hotmail.com
}

\section{RESUMO}

Este artigo apresenta uma experiência desenvolvida em duas disciplinas, ministradas nos cursos de licenciatura e bacharelado em Educação Física, e tem o objetivo de debater a relevância de pesquisas interventivas na formação dos acadêmicos, tanto no sentido de conhecer diferentes realidades de atuação profissional quanto na aprendizagem de procedimentos de pesquisa, ou seja, é um momento de aprendizagem teórica e prática, com possibilidades de intervenção a partir de um estudo prévio e de sugestões de melhorias a serem efetivadas em cada local. No entanto, o que se percebe é que nem sempre os objetivos das disciplinas são alcançados na totalidade, pois as pesquisas se mostram incipientes, e os acadêmicos não demonstram o domínio do conhecimento sobre pesquisa interventiva, essencial para o desenvolvimento do trabalho, e nem mesmo da leitura e escrita, primordiais em todas as etapas da investigação. A fundamentação teórica utiliza autores como Brandão (1984; 1985), Demo (1984; 1995; 1996), Le Boterf (1984) e Thiollent (1984). A metodologia de pesquisa consistiu em relato de experiência a partir da vivência das disciplinas ministradas nos dois cursos de graduação, por meio dos trabalhos dos alunos que desenvolveram a pesquisa interventiva. Percebe-se, com os relatórios finais apresentados, que há uma tentativa de conhecer de forma mais profunda o campo investigado, e de contribuir com a realidade encontrada, mas os alunos pesquisadores têm dificuldade em sistematizar o trabalho e em analisar os dados coletados, por mais que tenham estudado o conteúdo teórico e recebido orientações em relação ao planejamento e desenvolvimento da pesquisa interventiva.

Palavras-chave: formação profissional; pesquisa interventiva; Educação Física.

\section{INTERVENTIONAL RESEARCH AND PROFESSIONAL FORMATION: DEVELOPED EXPERIENCES ON PHYSICAL EDUCATION GRADUATES OF} UFG / REJ / BRAZIL

\begin{abstract}
This article presents an experience developed in two subjects on Physical Education graduate, major and bachelor's degree, and purposes to discuss the interventional research in academics' formation relevance, both to know different professional practice realities as learning of research procedures, that is, it is a theoretical and practical learning moment, with intervention possibilities from a previous study and improvements suggestions to be increased in each location. However, it is perceived that the subjects' purpose hardly ever totally reached, since researches are incipient, and academics do not demonstrate the knowledge field on interventional research, essential to the work development, and even of reading and writing, paramount in all the research stages. The theoretical foundation uses authors as Brandão (1984; 1985), Demo (1984; 1995; 1996), Le Boterf (1984) and Thiollent (1984). The research methodology consisted on experience report from what has been

${ }^{1} \mathrm{O}$ resumo deste artigo foi publicado nos anais do $1^{\circ}$ Congresso Ibero-Americano: Desporto, Educação, Atividade Física e Saúde, em Lisboa, Portugal, de 22 a 25 de outubro de 2015. Vinculação: Nesec/CNPq.
\end{abstract}


experienced on the subjects taught in both undergraduate, through the work made by students who developed interventional research. It is perceived, with the final reports presented, there is an attempt to understand deeply the field investigated, and to contribute to the found reality, but students researchers find it difficult to systematize the work and to analyze the data collected, however they have studied the theoretical content and received guidance on the planning and interventional research development.

Keywords: Professional formation; interventional research; Physical Education

\section{Introdução}

Atualmente, a Educação Física tem se apropriado de pesquisas interventivas para o desenvolvimento de investigações, as quais Demo (1995) caracteriza como comprometidas com intervenções que contemplam o autodiagnóstico, a construção de estratégia de enfrentamento e a organização política. Este trabalho relata o desenvolvimento deste tipo de pesquisa como foco das disciplinas Oficina Experimental I e II, nos cursos de licenciatura e bacharelado em Educação Física (EF) da Universidade Federal de Goiás (UFG), Regional Jataí (REJ), Brasil, ao longo do ano de 2014. As disciplinas ocorrem no quinto e sexto períodos dos cursos de bacharelado e de licenciatura, e como metodologia de ensino, os alunos vão a campo sob a orientação da professora responsável, para desenvolver as etapas da pesquisa participante e da pesquisa ação.

Para discorrer sobre a temática, este artigo foi estruturado em três partes: exposição dos objetivos da disciplina e organização das atividades durante o ano letivo, a experiência dos acadêmicos durante o ano de 2014, e algumas reflexões sobre as contribuições deste trabalho para a formação dos alunos.

\section{As disciplinas Oficina Experimental I e II e a organização das atividades}

As disciplinas Oficina Experimental ocorrem em dois semestres consecutivos e são denominadas I e II. As ementas de cada disciplina (I e II) são:

Oficina Experimental I: Prática de observação, reflexão, estudos e pesquisas em diferentes ambientes que tratam dos elementos da cultura corporal e que constituem campo de trabalho do professor de Educação Física. Estudo das principais metodologias de pesquisas participativas. Construção de projeto de intervenção referente aos problemas da realidade social no campo da Educação Física (UFG, 2011, p. 45).

Oficina Experimental II: Aprofundamento no estudo das metodologias participativas com ênfase na pesquisa-ação. Intervenção com foco na pesquisa-ação, abordando temas relacionados a cultura corporal e/ou outros aspectos que constituem campo de trabalho do professor de Educação Física. Elaboração de relatório(s) sobre as experiências interventivas (UFG, 2011, p. 46).

Percebe-se que a disciplina Oficina Experimental I, que ocorre no primeiro semestre, é responsável pela escolha e caracterização do campo de pesquisa, identificando os elementos que constituirão o projeto de pesquisa a ser desenvolvido. Ao mesmo tempo, os alunos desenvolvem 
estudos teóricos em sala de aula, para entenderem o que é uma pesquisa participante e uma pesquisa ação e como desenvolver o projeto de intervenção. O trabalho de conclusão da disciplina é a elaboração do projeto interventivo, feito em grupo.

No segundo semestre, a disciplina Oficina Experimental II visa o aprofundamento teórico no estudo das metodologias de pesquisa participante e pesquisa ação, e trabalha com o desenvolvimento da investigação que foi planejada no primeiro semestre. O projeto elaborado pelo grupo, com acompanhamento da professora das disciplinas, será desenvolvido, analisado e o produto final constitui-se no relatório da pesquisa realizada.

As ementas citadas são idênticas às disponíveis no projeto pedagógico do curso de bacharelado (UFG, 2012), diferenciando-se apenas na escolha dos campos de pesquisa. Quando os alunos iniciam a disciplina Oficina Experimental I, são orientados a procurarem locais para o desenvolvimento da investigação, de preferência que não sejam áreas de atuação que eles conhecem durante seu curso, isto é, que não sejam geralmente visitados (ou que foram pouco experienciados), tanto durante o estágio quanto nas aulas práticas das disciplinas. A intenção é possibilitar aos alunos de ambos os cursos a vivência de espaços diferentes e que eles aspiram conhecer. Desta forma, entende-se que a experiência será um complemento à formação acadêmica no sentido de vislumbrar novas possibilidades de atuação profissional e de conhecimento teórico-prático, ampliando o universo de vivências durante o curso superior.

O método de pesquisa utilizado durante as duas disciplinas é interventivo - pesquisa participante ou pesquisa ação - que possibilita o contato direto do pesquisador com o meio investigado. A pesquisa interventiva emergiu com credibilidade no meio educacional e científico, por volta de 1975, apoiada no paradigma crítico-dialético, e vem tomando espaço na produção científica da área da Educação desde então. No entender de Demo (1984), este tipo de pesquisa, incluindo a pesquisa participante, representou uma contraproposta aos métodos tradicionais, mas que apresenta fragilidades metodológicas, “desde a pretensão vã de se constituir na única forma válida de pesquisa, até posturas meramente ativistas que banalizam não só a ideia de pesquisa, mas também a ideia de participação" (DEMO, 1984, p. 104). Trata-se de uma metodologia alternativa, comprometida com intervenções que envolvem o autodiagnóstico, a construção de um enfrentamento prático dos problemas detectados e a organização política da comunidade (DEMO, 1995).

A opção por pesquisa participante ou pesquisa ação depende de cada grupo de alunos e das especificidades da realidade encontrada no local de investigação. O contato inicial com a instituição escolhida é feito no primeiro semestre, na disciplina Oficina Experimental I, por cada 
grupo de alunos e com acompanhamento da docente responsável. Em seguida fazem as observações não participantes, caracterizam o local de pesquisa e elaboram o projeto de intervenção. No segundo semestre, já na disciplina Oficina Experimental II, desenvolvem a pesquisa ação ou a pesquisa participante, com apoio de instrumentos de coleta de dados variados. Ao final do segundo semestre é feita a análise de todo o processo de pesquisa e elaborado um relatório final.

As etapas da pesquisa realizada pelos grupos de alunos seguem as fases enumeradas por Demo (1984) para o desenvolvimento da pesquisa participante: a primeira, exploração geral da comunidade, com fixação de objetivos, seleção de variáveis e de instrumentos de pesquisa, realização da pesquisa e síntese; a segunda, identificação das necessidades básicas, com elaboração do problema de pesquisa, nova seleção de variáveis e de instrumentos, realização da pesquisa, análise e síntese; e a terceira, elaboração de uma estratégia educativa, com elaboração de estratégias hipotéticas, elaboração de dispositivo de comprovação, discussão com o público envolvido, comunidade assume estratégia e execução. Estas fases ocorrem em processo denominado pelo autor de retroalimentação ${ }^{2}$, ao terminar cada fase, com o intuito de "identificar as necessidades; formular estratégia de ataque; levantar os recursos disponíveis; partir para soluções” (DEMO, 1984, p. 125). A adoção destas etapas, independente da opção dos grupos pelo desenvolvimento de pesquisa participante ou da pesquisa ação, fundamenta-se na clareza da justificativa de Thiollent (1984) de que muitas vezes estas expressões são consideradas como sinônimas, ou quase sinônimas, embora não o sejam, pois existe uma clara distinção: a pesquisa ação é uma forma de pesquisa participante, no entanto, nem todas as pesquisas participantes realizadas se constituem em pesquisa ação. De acordo com Thiollent (1984), a pesquisa ação pressupõe, além da ação planejada, uma intervenção associada a ações culturais, educacionais, organizacionais, políticas, dentre outras. Portanto, os grupos definem, ao fazer o projeto de pesquisa, qual será o tipo de pesquisa interventiva desenvolvida, e para isso é preciso ter claro quais são as etapas a serem cumpridas e a finalização que se espera. Por isso considera-se que os passos para desenvolver qualquer tipo de pesquisa interventiva passam pelas fases citadas por Demo (1984), com ênfase diferenciada ao final, na terceira fase, quando se opta pela pesquisa participante ou pela pesquisa ação.

\footnotetext{
${ }^{2}$ A retroalimentação ou feedback, de acordo com Le Boterf (1984, p. 68-69), “consiste numa atividade de 'retorno’ das informações colhidas no decorrer de uma pesquisa àqueles que foram pesquisados. Os resultados da pesquisas serão então colocados em discussão. As modificações alcançadas e as reações dos participantes serão introduzidas no próprio processo da pesquisa. Tal atividade não pode ser neutra ou desprovida de interesses, visto que o retorno da informação é sempre um ato político".
} 
As disciplinas Oficina Experimental I e II utilizam como referencial básico o material produzido por Brandão (1984; 1985), Demo (1984; 1995; 1996), Thiollent (1984), Triviños (1987), Gil (2012), dentre outros.

\section{A experiência dos acadêmicos das disciplinas Oficina Experimental I e II}

Durante o ano de 2014 foi desenvolvido um trabalho com seis grupos de alunos pesquisadores: dois do curso de licenciatura e quatro do curso de bacharelado. Cada grupo foi constituído por aproximadamente cinco alunos.

Os grupos da licenciatura escolheram como campo de intervenção: uma casa de cultura filantrópica, que atende a crianças em fase escolar e desenvolve atividades de artes, música, literatura, informática, atividades esportivas e recreativas, dentre outras; e um condomínio de residências de pessoas idosas, que moram sozinhas e que não precisam de ajuda para suas atividades cotidianas.

Os grupos do bacharelado procuraram as seguintes instituições: uma creche filantrópica para crianças em fase escolar e que vão para este local no contra turno das suas aulas na escola; uma fazenda de recuperação para dependentes químicos, todos do sexo masculino, sob a direção de uma entidade religiosa; um órgão de atendimento ao público, vinculado ao estado de Goiás, com funcionários que desempenham seus trabalhos sentados em frente aos computadores, grande parte do dia; e um estabelecimento comercial com funcionários que trabalham em torno de oito horas por dia com atividades repetitivas.

Para um melhor entendimento sobre o desenvolvimento do trabalho desenvolvido, segue uma breve exposição das atividades e resultados que cada grupo apresentou em seu relatório final de pesquisa. $^{3}$

\section{Casa de cultura}

A pesquisa desenvolvida pelo grupo da licenciatura nesta instituição se intitulou “Atividades de recreação para crianças da instituição casa de cultura". Trata-se de um centro de arte educacional e esportivo para crianças, organização pertencente ao terceiro setor, de caráter filantrópico, constituída por iniciativa voluntária.

\footnotetext{
${ }^{3}$ Os nomes das instituições foram substituídos para garantir o anonimato dos sujeitos e alguns títulos sofreram pequenas alterações, pelo mesmo motivo.
} 
Os oito professores que atuam na instituição são graduados nas áreas de Pedagogia, Educação Física, Psicologia, Artes Cênicas, e trabalham com as oficinas de leitura, natação, teatro, música, leitura, artes manuais, informática e as próprias aulas de Educação Física.

O espaço físico é privilegiado, pois contém uma estrutura suficiente para atender ao público, constituído de crianças entre seis e quatorze anos que estudam nas escolas públicas e que pertencem a famílias de baixa renda. No entanto, por ser filantrópica, a instituição depende de doações para se manter e faltam materiais para as aulas, bem como professores suficientes para atender a todas as turmas. Mesmo com ajuda de voluntários, a falta de pessoal é uma dificuldade constante.

Um dos problemas detectados pelo grupo na fase de observação, e que se constituiu no ponto central do desenvolvimento da pesquisa, foi a escassez de atividades da área de Educação Física e a ausência de professores suficientes, desta disciplina, para desenvolver outros conteúdos com os alunos. Isto, segundo a coordenação do local, se deve à dificuldade financeira em contratar profissionais de áreas específicas. Além disso, as experiências motoras dos alunos, neste espaço, se limitam às aulas de natação e de capoeira.

Diante disso, o grupo decidiu fazer um projeto de intervenção para trabalhar com os conteúdos da Educação Física que não são realizados na instituição, como: desporto, ginástica, jogos e brincadeiras e dança, com o objetivo de proporcionar aos alunos vivências desses conteúdos, bem como despertar para a necessidade de se investir na contratação de um professor específico para esta prática, na instituição. A opção por estes conteúdos parte da proposta apresentada pelo Coletivo de Autores (1992) e da explicação de Jeber (1997, p.123) de que a Educação Física é uma prática pedagógica e social, que busca desenvolver e constituir o movimento corporal humano "[...] enquanto conhecimento, expressão, prazer, integração pessoal e social, de modo questionador/transformador.”. A proposta de intervenção previu, além de trabalhar com os conteúdos específicos, contribuir com a formação humana e social das crianças.

No relatório final, o grupo expôs que, a partir da intervenção, foi possível perceber certa mudança no comportamento das crianças, durante as aulas de Educação Física, pois alguns alunos que eram muitos tímidos no início das atividades, no decorrer das regências tiveram um bom desenvolvimento participativo. Outras situações de cooperação, respeito ao próximo e interação nas aulas foram percebidas. Além disso, foi reforçada a necessidade de existir mais práticas corporais no espaço, principalmente considerando-se a faixa etária das crianças.

Essa conclusão à qual chegaram os alunos pesquisadores coincide com a análise de Darido e Rangel (2005) sobre os conteúdos da Educação Física que trabalham as dimensões 
conceitual, procedimental e atitudinal. Os valores, hábitos, habilidades, modos valorativos e atitudinais da atuação social podem ser utilizados nas aulas e aplicados pelos alunos em sua vida cotidiana. No entender das autoras, "para facilitar a adesão dos alunos às práticas corporais, seria importante diversificar as vivências experimentadas nas aulas, para além dos esportes tradicionais" (p. 72), isto é, a possibilidade de vivenciar outras atividades como ginástica, jogos, lutas, brincadeiras, danças, podem aumentar o interesse e a participação dos alunos nas aulas. E, além disso, podem contribuir com a formação dessas crianças para a vida, pois, como afirma Kuhlmann Júnior (2001, p. 11), “[...] a educação não é um fenômeno que aconteça e permaneça no interior do âmbito educacional". Pode-se assegurar, portanto, que toda aprendizagem deve ser significativa, ter sentido e aplicabilidade para as crianças em formação.

No entanto, apesar da presença do grupo pesquisador e da tentativa de empreender mudanças no espaço investigado, não foi possível empreender uma intervenção que modificasse a realidade desta instituição. Apenas se mostrou a relevância deste tipo de atividade e a necessidade de um (ou mais de um) profissional da área de Educação Física.

\section{Condomínio residencial de pessoas idosas}

O outro grupo de alunos da licenciatura desenvolveu a pesquisa no condomínio composto por residências de pessoas da terceira idade, e o trabalho recebeu o título de "!Projeto de Oficina Experimental”. Este condomínio é um lar de idosos, constituído de trinta pequenas casas e de áreas em comum, contendo piscina, salão de festas, horta, ambulatório, pátio e salas para atividades específicas. É mantido pelo município, com o auxílio de doações da comunidade. Todos os moradores são idosos aposentados, que geralmente recebem em torno de um ou dois salários mínimos de aposentadoria e se mantêm sem ajuda de terceiros para desempenhar suas atividades cotidianas.

Neste espaço trabalham dez funcionários, mas nenhum professor de Educação Física. São ofertadas atividades físicas apenas por meio de projetos temporários e colaboradores voluntários. No entanto, outras atividades são disponibilizadas para os moradores, como aulas de pintura, crochê, cuidados com a horta, dentre outras.

Como todos os moradores têm acima de sessenta anos e a maior parte das atividades realizadas por eles são na posição sentada, sem muito esforço físico, eles não se interessam, em sua maioria, pela prática de exercícios físicos, independente da modalidade ofertada. Por meio das observações, o grupo percebeu que um dos primeiros impasses seria convencê-los da importância de se exercitar e convidá-los a praticar algum tipo de atividade. 
Após conversas informais, visita a cada morador do condomínio e exposição da necessidade de se exercitar, o grupo elaborou uma proposta de intervenção constituída por aulas de dança, ginástica e jogos e brincadeiras. O objetivo da pesquisa interventiva, portanto, foi desenvolver exercícios físicos planejados para um grupo de terceira idade, na intenção de contribuir com a conscientização sobre a importância da Educação Física como um meio imprescindível para a melhoria e/ou manutenção da saúde e como forma diversificada de lazer.

As atividades desenvolvidas foram planejadas a partir da necessidade dos idosos de realizarem algum tipo de exercício, visando a manutenção ou a melhoria de suas condições de saúde (MACIEL, 2010; REIS, 2012). Aproximadamente doze idosos participaram das aulas, mas esse número oscilava e houve dias em que apenas dois compareceram. O relato final dos participantes foi de que alguns sentiram melhora na disposição para desempenhar suas tarefas diárias, as dores no corpo e as dificuldades de locomoção foram minimizadas, houve melhoria na qualidade do sono, dentre outras. São resultados que confirmam a afirmação de Santos, Andrade e Bueno (2009) de que o envelhecimento é um processo de degradação progressiva e diferencial que afeta todos os seres vivos, e o aumento da expectativa de vida tem sido evidenciada pelos avanços tecnológicos relacionados à área de saúde, aliados aos bons hábitos de vida. Dentre eles, a prática de atividades físicas regulares.

Os resultados encontrados nesta pesquisa interventiva também coincidem com a afirmação de Mota et al (2006) sobre a utilidade da atividade física como elemento que auxilia as pessoas idosas a se ajustarem às alterações, tanto físicas, funcionais e emocionais, quanto de seu papel na sociedade, pois em muitos casos as pessoas mais velhas precisam renunciar aos papéis considerados por elas como parte significativa de sua identidade, profissionalmente e na vida familiar.

Neste projeto também não foi possível perceber uma intervenção no sentido de mudar a realidade do local investigado, mas verificou-se que, pelo menos parcialmente, os idosos que participaram das aulas com maior frequência demonstraram interesse em continuar praticando algum tipo de atividade física, depois que o projeto se encerrasse. Além dos benefícios físicos, as aulas se tornaram um espaço de interação entre estas pessoas que moram no mesmo local, mas que nem sempre se relacionam, melhorando as condições de socialização e convívio no condomínio. Estes resultados também se assemelham aos estudos realizados por Mota et al (2006), sobre a prática de atividade física oportunizar o alargamento das relações sociais, pois estimula novos contatos e possíveis laços de amizade, exercendo efeitos saudáveis em nível cognitivo e de qualidade de vida. 


\section{Creche filantrópica}

Um dos grupos do bacharelado desenvolveu sua pesquisa na creche filantrópica, mantida por uma entidade religiosa evangélica, com ajuda da comunidade. O título do relatório final é Recreação para crianças na creche. Esta instituição atende às crianças de seis a doze anos que estudam, portanto, elas vão para o local no contra turno das suas aulas. Ao todo, são atendidas aproximadamente sessenta crianças, nos dois turnos (matutino e vespertino).

Trabalham na creche apenas três pessoas: uma cozinheira e três voluntárias, uma das quais ocupa o cargo de diretora. As atividades realizadas com as crianças são: tarefas da escola, que são feitas na creche; brincadeiras informais com os brinquedos disponíveis; estudos bíblicos e orações; trabalhos manuais; filmes; computação; dentre outras.

O problema detectado nesta instituição foi a falta de atividades físicas programadas e direcionadas à faixa etária atendida. Não havia professor de Educação Física disponível e as atividades recreativas ocorriam de forma isolada, de acordo com a vontade das crianças. Portanto, o grupo definiu como objetivo ofertar atividades recreativas para as crianças por meio de jogos e brincadeiras, visando estimular a criatividade e criar condições de interação e de vivência dos conteúdos da Educação Física. Foram trabalhados os seguintes conteúdos: jogos tradicionais, trabalhos manuais, atividades com música e jogos esportivos adaptados. Baecker (2001) afirma que é muito importante a criança se movimentar, pois a experiência corporal lhe permite aprender conceitos e ações, desenvolver sua consciência própria e individualidade, independência, amadurecimento cognitivo, percepção e configuração artística, dentre outros. O grupo procurou, nas aulas ministradas, ir além dos objetivos das atividades específicas.

Como resultado apresentado no relatório final, foi destacada a mudança de comportamento dos alunos no sentido de organização, cooperação e respeito às diferenças de gênero, itens que coincidem com o que os autores como Coletivo de Autores (1992), Darido e Rangel (2005), dentre outros, defendem sobre a necessidade de se trabalhar com os conteúdos da Educação Física dentro de uma perspectiva que contemple a formação crítico-social e humana, voltada para a cultura corporal de movimento.

A direção da creche demonstrou reconhecer a falta de um professor de Educação Física para trabalhar com as crianças e pareceu sensível à necessidade de se buscar formas de solucionar este problema, seja por meio de solicitação à prefeitura para disponibilizar um professor para a creche, seja buscando a contratação deste profissional por outros meios. Para Darido e Rangel (2005), a presença deste docente no trato com as crianças permite não só a mediação entre ensino e 
aprendizagem, mas também o estabelecimento de interação direta com os alunos, relacionando aspectos cognitivos, intelectuais, emocionais e sociais que podem transmitir valores, formas de pensar, normas, padrões de comportamentos, dentre outros, seja de forma consciente ou não.

Pode-se afirmar que, de alguma forma, a intervenção realizada afetou o cotidiano desta instituição e algumas mudanças poderão ser empreendidas, depois desta experiência, apesar de não se ter notícias da contratação do professor de Educação Física até o momento de conclusão e apresentação do relatório final.

\section{Fazenda de recuperação de dependentes químicos}

O grupo que desenvolveu a pesquisa na fazenda de recuperação de dependentes químicos intitulou seu relatório final de Atividades cooperativas desenvolvidas pelo profissional da Educação Física no local de tratamento dos adictos. Trata-se de uma instituição filantrópica, mantida por uma instituição religiosa evangélica e com ajuda da comunidade. O local atende aproximadamente quarenta pessoas que têm qualquer tipo de dependência química, predominantemente de classe social baixa, de treze a setenta anos. A fazenda possui duas casas e um espaço amplo para atender aos adictos.

A direção é composta por quatro membros, vinculados à igreja evangélica, e há três cooperadores no local, ex-dependentes químicos que agora ajudam na organização e nas atividades cotidianas da fazenda.

Assim como os demais locais, não há profissional de Educação Física que atenda ao grupo, seja contratado, seja voluntário. Também não há recursos materiais e espaço físico disponível para a prática de atividades físicas, exceto um campo de futebol improvisado, uma mesa de tênis de mesa, e uma de pebolim. No entanto, o acesso dos adictos às atividades de lazer é restrito. As atividades desenvolvidas são, prioritariamente, a doutrina religiosa, por meio de estudos bíblicos, filmes e músicas religiosas, e as atividades cotidianas de limpeza dos espaços, da cozinha, cuidados com as roupas, com a horta e com os animais da fazenda.

Diante das observações realizadas, o grupo percebeu que os internos precisam de exercícios físicos para complementar suas atividades diárias, e que nem todos se interessam por isso, seja por limitações físicas, por idade avançada ou por opção. Foram planejados jogos cooperativos com o objetivo de promover a interação, a cooperação e a socialização dos adictos, contribuindo para a melhoria de suas condições físicas, inclusive no processo de desintoxicação, pois a transpiração é um veículo de excreção das substâncias tóxicas do organismo (KIDWELL et 
al, citados por PIMENTEL et al, 2008). Além disso, muitos dos efeitos positivos do exercício sobre a saúde mental têm sido atribuídos à indução da produção de endorfina (WERNECK; BARA FILHO; RIBEIRO, 2005).

O objetivo geral da investigação foi promover, por meio da pesquisa interventiva, a conscientização da importância da prática de atividades físicas pelos adictos para manutenção do bem-estar físico e social. Pode-se afirmar que este foi um grupo que conseguiu promover mudanças de comportamento e de conscientização no local de pesquisa, pois no decorrer do ano percebeu-se uma inclusão voluntária de práticas esportivas na programação cotidiana, mesmo na ausência dos pesquisadores; maior interesse pelos exercícios, inclusive por parte dos adictos mais idosos; e, principalmente, a mudança de opinião sobre a relevância desta prática para a melhoria das condições físicas e psicológicas durante a recuperação da dependência química.

Os resultados encontrados pelos alunos pesquisadores se assemelham ao estudo de Schmidt (2007), que apresenta o exercício físico como

\begin{abstract}
influenciador positivo no tratamento para dependência química, principalmente como auxiliar na ocupação do tempo e na manutenção da abstinência. O exercício físico foi percebido positivamente como influenciador do bem-estar psicológico e foi associado ao gosto pela atividade, favorecimento do relaxamento, melhora na disposição, alívio nos pensamentos, melhora na auto-estima, inclusão nos objetivos e metas para o futuro, incremento nas relações sociais, incentivo às sensações de superação, compromisso e responsabilidade. As melhoras percebidas no bem-estar físico foram, principalmente, em relação à melhora no tônus e força muscular, capacidade aeróbica e sono (p. 4).
\end{abstract}

Assim como a autora concluiu que o exercício físico é um fenômeno que influencia positivamente no bom humor e na sensação de bem-estar do grupo de dependentes químicos, esses resultados foram denotados também durante a pesquisa interventiva desenvolvida pelos acadêmicos. Da mesma forma, outros estudos, como os de Ferreira (2012) e de Mialick, Fracasso e Sahd (2013), corroboram que esta prática pode ser coadjuvante no tratamento da dependência química, por gerar a sensação de bem-estar físico e mental e de prazer, suprindo a falta das substâncias psicoativas no organismo.

No início, houve relatos de não se praticar exercícios físicos por muitos acreditarem que as práticas esportivas os afastavam de uma vida espiritual plena. Esta mudança de opinião e a maior informação sobre os benefícios da prática contínua de exercícios físicos foi um dos melhores resultados obtidos durante a intervenção.

\title{
Órgão de atendimento ao público
}


Outro grupo do bacharelado optou por desenvolver a pesquisa em espaço de trabalhadores, e escolheu um órgão que tem a intenção de facilitar o acesso dos cidadãos aos serviços de interesse público. O título atribuído foi "Ginástica laboral como promoção da saúde e melhoria da qualidade de vida dos funcionários de um órgão de atendimento ao público".

Neste local, trabalham sessenta funcionários, cada um deles qualificado para sua área de atendimento, e todos trabalham oito horas diárias, sentados em frente às suas mesas, com computador. Não há nenhum profissional de Educação Física que trabalhe com atividades físicas, seja ginástica laboral ou qualquer outro tipo de exercícios programados. Portanto, ao observar a rotina de trabalho destes funcionários, o grupo estabeleceu como objetivo geral da pesquisa: contribuir para a melhoria na qualidade de vida dos funcionários da instituição, por meio da implantação do projeto interventivo de ginástica laboral e do incentivo aos hábitos saudáveis e à prática de exercícios de compensação. Partiu-se do princípio de que a ginástica laboral proporciona benefícios que contemplam, além do bem estar físico, o autoconhecimento e o relacionamento com o grupo, contribuindo para a melhoria da qualidade de vida (BASSO, 1989).

Foi aplicado um questionário no início da pesquisa e outro ao final, inicialmente para se obter maior conhecimento sobre a rotina e as necessidades de cada funcionário e, posteriormente, para verificar a opinião deles sobre possíveis benefícios (ou não) proporcionados pela ginástica laboral. Os dados coletados permitiram planejar o processo interventivo de forma direcionada e avaliar os efeitos e resultados da pesquisa desenvolvida.

Apesar da inconstância no número de participantes, as pessoas que responderam aos questionários e que participaram das aulas relataram melhorias relacionadas a: postura, relaxamento muscular, prevenção e diminuição de dores no corpo, alteração do humor, conscientização da importância das atividades físicas, entre outros. Os dados encontrados se assemelham aos estudos sobre os efeitos benéficos da ginástica laboral, divulgados por Viana, Benini e Vasconcellos (2011), Brito e Martins (2012), Ferreira e Santos (2013), dentre outros.

No entanto, não se pode dizer que o projeto mudou a realidade do local e dos participantes, pois não houve manifestação de interesse dos gestores pela contratação de profissional da área de Educação Física para desenvolver atividades laborais com os funcionários. Houve, apenas, por parte dos próprios funcionários, a ampliação do interesse pela busca de atividades físicas diárias para contribuir na melhoria de seu bem estar geral.

\section{Estabelecimento comercial}


Outro grupo procurou um estabelecimento comercial para desenvolver a pesquisa, com a intenção de trabalhar com a ginástica laboral. O título do relatório final é "A ginástica laboral e as contribuições na melhoria da qualidade de vida dos funcionários da empresa investigada”. A empresa selecionada presta serviços no ramo de telefonia, e tem sete funcionários contratados, com faixa etária entre dezoito e trinta anos. Como todos os outros grupos, neste espaço também não há professor de Educação Física trabalhando com as pessoas que permanecem sentadas o dia todo, realizando movimentos repetitivos de atendimento ao público, seja pessoalmente, seja por telefone.

O sedentarismo não foi um problema detectado pelo grupo, durante a investigação, pois a maior parte deles pratica algum tipo de atividade física fora do horário de trabalho. A repetição contínua de movimentos e a permanência por muito tempo na posição sentada foram os principais itens destacados. Portanto, o objetivo da pesquisa desenvolvida por este grupo foi contribuir na melhoria da qualidade de vida dos funcionários, por meio da ginástica laboral, considerando os benefícios comprovados por vários estudos, como os de Ferreira e Santos (2013) e de Sampaio e Oliveira (2008).

Foi aplicado um questionário inicial, para conhecer os sujeitos e para utilizar as informações no planejamento das atividades laborais. Percebeu-se, com os resultados da pesquisa, que houve maior satisfação dos funcionários no desempenho das atividades cotidianas de trabalho, melhor disposição física e psicológica e maior interação entre os colegas. Estes resultados coincidem com os estudos de Viana, Benini e Vasconcellos (2011), Brito e Martins (2012), dentre outros.

Isto despertou, nos sujeitos, maior conscientização pela necessidade de praticar algum tipo de exercício físico regular. Nessa direção, Brito e Martins (2012) afirmam que a ginástica laboral contribui para a mudança de estilo de vida, que passa a ser mais ativo fisicamente e com alimentação saudável. No entender das autoras, o trabalhador passa a maior parte do dia no ambiente de trabalho e nem sempre se preocupa com sua qualidade de vida e com os hábitos de saúde adotados.

No entanto, as alterações percebidas na pesquisa desenvolvida pelos alunos foram superficiais e não conseguiram atingir o objetivo de mudança da realidade investigada, principalmente por parte da gerência da empresa, que não manifestou interesse em contratação de profissional qualificado para trabalhar a ginástica laboral com seus funcionários.

\section{Dificuldades dos acadêmicos no desenvolvimento da pesquisa interventiva}


Durante o desenvolvimento das disciplinas Oficina Experimental I e II, percebeu-se algumas limitações dos acadêmicos, tanto na realização dos estudos teóricos quanto na operacionalização da pesquisa interventiva. Antecedendo as dificuldades inerentes à formação dos alunos para realizar tipo de pesquisa, Demo (1984) cita que a própria pesquisa interventiva oferece fragilidades, como por exemplo, as banalizações excessivas, as limitações da articulação entre teoria e prática, o desconhecimento de como desenvolver uma pesquisa dialética, a dificuldade em se manter o equilíbrio entre o objetivo material e o subjetivo político, em sistematizar a crítica da realidade social vigente e encontrada, bem como em mobilizar o grupo investigado em busca de algum tipo de transformação. Estas dificuldades, no entender do autor, em grande parte se devem ao caráter incipiente da pesquisa interventiva. Portanto, se este tipo de investigação, para além de sua complexidade, precisa ser encaminhada por pesquisadores iniciantes, é quase óbvio que os problemas e dificuldades surgirão.

O conhecimento sobre o que caracteriza este tipo de pesquisa, quais são seus fundamentos e técnicas, seus objetivos e proposta, parece ser de difícil compreensão para os alunos, que tiveram alguns entraves na leitura e discussão dos textos, na elaboração de respostas escritas para trabalhos realizados em sala e principalmente na utilização destes conhecimentos na pesquisa de campo.

As dificuldades se tornaram maiores quando foi preciso planejar a intervenção, desenvolver as atividades previstas e escrever o relatório final, pois a falta de fundamentação teórica compromete o bom andamento dos trabalhos, que requisitou o acompanhamento da professora, como orientadora, de forma intensiva, do início ao fim da pesquisa. A organização do pensamento escrito, essencial no momento de sistematização do relatório final, não se concretizou, e como produto de todo esse processo obteve-se a apresentação de resultados superficiais que requerem aprimoramento e aprofundamento na descrição e discussão dos resultados ${ }^{4}$.

As limitações de leitura e escrita por parte de estudantes de cursos de graduação são constantes, como comprovam alguns estudos, dentre eles os de Cardoso (2008) e Tourinho (2011). A falta de compreensão do referencial teórico e a complexidade de transformar o pensamento em texto comprometem o desenvolvimento da pesquisa, desde a fase de planejamento, passando pela intervenção e culminando na sistematização escrita dos resultados. Para Tourinho (2011, p. 333), "o ato de ler é uma atividade que implica não somente a decodificação de símbolos; envolve uma série de estratégias que permitem ao indivíduo compreender o que lê”. A pesquisa durante o curso

\footnotetext{
${ }^{4}$ Ressalte-se que não se trata de generalização. Todos os grupos, tanto da licenciatura quanto do bacharelado, apresentaram as dificuldades citadas.
} 
de formação constitui-se um locus privilegiado de produção do conhecimento, pois requer do acadêmico a aquisição e o exercício de certas habilidades, dentre elas a leitura e a escrita.

Corroborando com este pensamento, Cardoso (2008, p. 1) confirma: "o trabalho com a pesquisa científica torna-se fundamental para o desenvolvimento dos acadêmicos, de modo que a compreensão do processo de pesquisa também precisa ser explicitado a eles". Portanto, no desenvolvimento das disciplinas Oficina Experimental I e II o aluno tem a oportunidade de vivenciar a pesquisa e, ao mesmo tempo, desenvolver a aptidão para a leitura e a escrita, que são essenciais ao crescimento e desenvolvimento profissional.

Tourinho (2011) afirma que o acadêmico precisa entender o que de fato significa a leitura. Ler apenas por ler não basta, ou seja, não se trata apenas de decodificar o texto, é preciso ter uma preparação prévia, de conhecimento de mundo, que permitirá ao estudante universitário estabelecer nexos entre suas atuais leituras e outras visões e concepções já internalizadas. No entender do autor, talvez este seja um dos problemas da dificuldade de leitura na graduação, pois é exigido dos graduandos um rol de conhecimentos prévios, provenientes do convívio social, das situações de debate, discussão, observação do mundo em sua volta, que permitam fazer ligação entre os temas que se lê e a bagagem adquirida.

Diante disso, pode-se afirmar, portanto, que a superficialidade com que as leituras ocorrem, durante o processo formativo, prejudicam a compreensão do que é lido e, consequentemente, comprometem a sistematização de ideias no formato escrito. Este tipo de dificuldade foi explícito durante o desenvolvimento das disciplinas, em todas as fases: de planejamento, de intervenção e de sistematização escrita dos resultados.

De acordo com pesquisa desenvolvida por Amaral (2010), os acadêmicos passam a ter uma visão diferente da pesquisa, após a experiência vivenciada na graduação, pois compreendem a necessidade deste tipo de aprendizagem para sua formação profissional. No entender do autor, os alunos mudam a forma de ver uma investigação científica a partir do momento que conhecem como o trabalho é feito. Isso reforça a intenção de continuar com as disciplinas no atual formato, pois os estudantes apenas aprenderão a fazer pesquisa, fazendo.

Em síntese, pode-se afirmar que, apesar das dificuldades, os grupos conseguiram desenvolver a proposta inicial. A realização da pesquisa interventiva nestas disciplinas conseguiu atingir seu intuito formador, embora não se possa esperar que a qualidade dos produtos finais seja similar às pesquisas realizadas por equipes de profissionais experientes e desenvolvidas em outros contextos, com condições específicas para este tipo de investigação. Acredita-se, portanto, que os 
objetivos das disciplinas Oficina Experimental I e II foram cumpridos, mesmo apresentando limitações.

\section{Contribuições deste trabalho para a formação dos alunos}

Compreende-se a importância da pesquisa na formação dos acadêmicos, assim como o ensino e a extensão. Esta disciplina, portanto, ultrapassa os limites do ensino e permite que os alunos ingressem o mundo da pesquisa, aprendendo métodos e técnicas que serão úteis não apenas no cumprimento do planejamento da Oficina Experimental I e II, mas no conhecimento de realidades diversificadas, com demandas latentes e problemas a serem solucionados. Embora nem todos os problemas detectados possam ser resolvidos, esta experiência contribui para um olhar diferenciado sobre a realidade, para a reflexão sobre a possível atuação profissional em áreas algumas vezes desconhecidas, e para a busca de conhecimentos teóricos que respaldem a investigação e a intervenção.

Este tipo de pesquisa torna-se relevante na formação dos acadêmicos dos cursos de Educação Física, pois, de acordo com Freire (1984), propõe um método de pesquisa alternativa em que se aprende a fazer por meio da ação. Esta disciplina permite que os acadêmicos conheçam, problematizem e intervenham em realidades que possivelmente não conheceriam durante seu curso de formação. A despeito das dificuldades de construção do conhecimento e de domínio metodológico, esta experiência, sem dúvida, contribui no processo formativo dos futuros profissionais de Educação Física.

E ainda, este trabalho desenvolvido pelos grupos de alunos apresenta o caráter de desvelamento de situações que existem e que podem ser melhoradas. A ausência de profissionais da área de Educação Física em campos férteis para o nosso trabalho é um dos principais pontos questionados pela maior parte dos grupos que desenvolveram a pesquisa no ano de 2014. Isto incita a reflexão e remete a outros fóruns de debate e de busca de condições e de espaços de trabalho que precisam ser divulgados.

\section{Algumas considerações}

Este artigo procurou relatar as experiências desenvolvidas por seis grupos de alunos das disciplinas Oficina Experimental I e II, que foram iniciados no mundo da investigação por meio de pesquisa interventiva, especificamente a pesquisa ação e a pesquisa participante. Procurou-se, a 
partir da exposição dos resultados que os grupos de pesquisa obtiveram, durante o desenvolvimento destas disciplinas, abordar a relevância das pesquisas interventivas como instrumento de formação acadêmica, pois possibilita a aproximação com diferentes realidades do mundo do trabalho e viabiliza a aprendizagem e realização dos procedimentos de pesquisa, permitindo a interação entre teoria e prática, bem como culminando na busca por melhorias e benefícios aos grupos investigados.

A pesquisa ação e a pesquisa participante requerem muita leitura, preparação e conhecimento por parte dos pesquisadores, pois, de acordo com Demo (1995), trata-se de uma forma de avaliar qualitativamente as manifestações sociais, e se apoiam no paradigma crítico dialético de produção científica. Portanto, nem sempre os objetivos da disciplina são alcançados, pois as pesquisas se mostram incipientes, e os pesquisadores (alunos) não demonstram nem mesmo o domínio do conhecimento primário sobre pesquisa interventiva, essencial para o desenvolvimento do trabalho. A leitura e a escrita também se constituem em empecilhos para o bom andamento da investigação. Percebe-se, com os relatórios finais apresentados, que há uma tentativa de conhecer de forma mais profunda o campo investigado, e de contribuir com a realidade encontrada, mas os pesquisadores têm dificuldade em sistematizar o trabalho e em analisar os dados coletados.

No entanto, este é um dos passos em direção à iniciação científica dos acadêmicos, que precisam incrementar sua formação, extrapolando os muros da sala de aula e os limites da universidade.

\section{Referências}

AMARAL, R. do. As contribuições da pesquisa científica na formação acadêmica. Identidade Científica, Presidente Prudente-SP, v. 1, n. 1, p. 64-74, jan./jun. 2010. Disponível em: <http://www.unoeste.br/facopp/revista_facopp/IC1/IC16.pdf>. Acesso em: 20 jun. 2015.

BAECKER, I. M. Vivência de movimento e Educação Física. In: SEMINÁRIO MUNICIPAL DE LAZER, ESPORTE E EDUCAÇÃO FÍSICA ESCOLAR, I, 2001, Santa Maria/RS. Anais... Santa Maria: Secretaria Municipal de Educação, 2001.

BASSO, A. L. Ginástica laboral: perspectiva de difusão no polo industrial de Piracicaba. 1989. Monografia (Conclusão de Curso) - Departamento de Educação Física, Universidade Estadual Paulista, Rio Claro, 1989. 
BRANDÃO, C. R. (Org.). Pesquisa participante. São Paulo: Brasiliense, 1984.

BRANDÃO, C. R. (Org.). Repensando a pesquisa participante. São Paulo: Brasiliense, 1985.

BRITO, E. C. de O.; MARTINS, C. de O. Percepção dos participantes de programa de Ginástica Laboral sobre flexibilidade e fatores relacionados a um estilo de vida saudável. Revista Brasileira em Promoção da Saúde, Fortaleza, v. 25, n. 4, p. 445-454, out./dez. 2012. Disponível em: < http://ojs.unifor.br/index.php/RBPS/article/view/2547/pdf>. Acesso em: 20 nov. 2015.

CARDOSO, R. D. Leitura e escrita na graduação - o texto científico. FAP Ciência, Apucarana-PR, v. 2, p. 1-9, 2008 set. Disponível em: <http://www.fap.com.br/fapciencia/002/edicao_2008/005.pdf>. Acesso em: 22 set. 2015.

COLETIVO DE AUTORES. Metodologia do ensino da Educação Física. São Paulo: Cortez, 1992.

DARIDO, S. C.; RANGEL, I. C. A. Educação Física na escola: implicações para a prática pedagógica. Rio de Janeiro: Guanabara Koogan, 2005.

DEMO, P. Educar pela pesquisa. Campinas: Autores Associados, 1996.

DEMO, P. Elementos metodológicos da pesquisa participante. In: BRANDÃO, C. R. (Org.). Repensando a pesquisa participante. São Paulo: Brasiliense, 1984. p. 104-130.

DEMO, P. Metodologia científica em Ciências Sociais. São Paulo: Atlas, 1995.

FERREIRA, G. F. de. Efeitos da atividade física no tratamento de dependentes químicos: uma revisão da literatura. EFDeportes.com, Revista Digital. Buenos Aires, año 15, n. 166, p. 1, mar. 2012. Disponível em: <http://www.efdeportes.com/efd166/atividade-fisica-no-tratamento-dedependentes-quimicos.htm>. Acesso em: 18 out. 2015.

FERREIRA, K. da S.; SANTOS, A. P. dos. Os benefícios da ginástica laboral e os possíveis motivos da não implantação. Revista Educação Física, Bebedouro-SP, Ano II, n. 2, p. 56-72, dez. 2013.

Disponível

em:

<http://unifafibe.com.br/revistasonline/arquivos/revistaeducacaofisica/sumario/29/16122013151810 .pdf>. Acesso em: 23 jun. 2014. 
FREIRE, P. Criando métodos de pesquisa alternativa: aprendendo a fazê-la melhor através da ação. In: BRANDÃO, C. R. (Org.). Pesquisa participante. São Paulo: Brasiliense, 1984. p. 34-41.

GIL, A. C. Métodos e técnicas de pesquisa social. São Paulo: Atlas, 2012.

JEBER, L. J. Plano de ensino em Educação Física escolar: um projeto político-pedagógico em ação. In: SOUSA, E. S. de; VAGO, T. M. (Orgs). Trilhas e partilhas: Educação Física na cultura escolar e nas práticas sociais. Belo Horizonte: Gráfica e Editora Cultura, 1997. p. 113-143.

KUHLMANN JÚNIOR, M. Infância e educação infantil: uma abordagem histórica. Porto Alegre: Mediação, 2001.

LE BOTERF, G. Pesquisa participante: propostas e reflexões metodológicas. In.: BRANDÃO, C. R. (Org.). Repensando a pesquisa participante. São Paulo: Brasiliense, 1984. p. 51-81.

MACIEL, M. G. Atividade física e funcionalidade do idoso. Motriz, Rio Claro, v.16, n.4, p.10241032, out./dez. 2010. Disponível em: <http://www.scielo.br/pdf/motriz/v16n4/a23v16n4>. Acesso em: 20 nov. 2015.

MIALICK, E. S.; FRACASSO, L; SAHD, S. M. P. V. A importância da prática de atividade física como auxílio no processo de tratamento para a dependência química em pessoas de 18 a 35 anos. Cooperativa do Fitness, 2013. Disponível em: <http://www.cdof.com.br/A\%20import\%E2ncia\%20da\%20pr\%E1tica\%20de\%20atividade\%20f\%E Dsica\%20como\%20aux\%EDlio\%20no\%20processo\%20de\%20tratamento\%20para\%20a\%20depen d\%EAncia\%20qu\%EDmica\%20em\%20pessoas\%20de\%2018\%20a\%2035\%20anos.pdf>. Acesso em: 20 nov. 2015.

MOTA, J. et al. Atividade física e qualidade de vida associada à saúde em idosos participantes e não participantes em programas regulares de atividade física. Revista Brasileira de Educação Física e Esporte, São Paulo, v. 20, n.3, p. 219-25, jul./set. 2006. Disponível em: < http://www.revistas.usp.br/rbefe/article/view/16629>. Acesso em: 18 nov. 2015.

PIMENTEL, G. G. de A. et al. Significado das práticas corporais no tratamento da dependência química. Interface Comunicação, Saúde, Educação, Botucatu-SP, v. 12, n. 24, p. 61-71, jan/mar. 2008. Disponível em <http://www.scielo.br/scielo.php?script=sci_arttext\&pid=S141432832008000100006>. Acesso em: 21 de jun. 2014 
REIS, A. Educação Física seu manual de saúde. São Paulo: Editora Difusão Cultural do Livro Ltda - CLD, 2012.

SAMPAIO, A. A.; OLIVEIRA, J. R. G. de. A ginástica laboral na promoção da saúde e melhoria da qualidade de vida no trabalho. Caderno de Educação Física, Marechal Cândido Rondon, v. 7, n. 13, p. 71-79, 2. $\quad$ sem. 2008. Disponível em: < http://www.cdof.com.br/artigo\%20Gin\%E1stica\%20Laboral\%20Adelar\%20e\%20Jo\%E3o.pdf>. Acesso em: 3 jul. 2014.

SANTOS, F. H. dos; ANDRADE, V. M.; BUENO, O. F. A. Envelhecimento: um processo multifatorial. Psicologia em Estudo, Maringá, v. 14, n. 1, p. 3-10, jan./mar. 2009. Disponível em: < http://www.scielo.br/scielo.php?script=sci_arttext\&pid=S1413-73722009000100002>. Acesso em: 18 nov. 2015.

SCHIMIDT, K. C. Exercício físico, humor e bem-estar na percepção de dependentes químicos em tratamento. 2007. Dissertação (Mestrado em Educação Física) - Programa de Pós-Graduação em Educação Física, Universidade Federal de Santa Catarina, Santa Catarina, 2007.

THIOLLENT, M. Notas para o debate sobre pesquisa-ação. In: BRANDÃO, C. R. (Org.). Repensando a pesquisa participante. São Paulo: Brasiliense, 1984. p. 82-103.

TOURINHO, C. Refletindo sobre a dificuldade de leitura em alunos do ensino superior: “deficiência” ou simples falta de hábito? Revista Lugares de Educação, Bananeiras-PB, v. 1, n. 2 , p. 325-346, jul/dez. 2011. Disponível em: 〈http://periodicos.ufpb.br/ojs2/index.php/rle〉. Acesso em: 22 set. 2015.

TRIVIÑOS, A. N. S. Introdução à pesquisa em ciências sociais: a pesquisa qualitativa em educação. São Paulo: Atlas, 1987.

UFG. Projeto Pedagógico do Curso de Educação Física - Licenciatura. Jataí-GO: Universidade Federal de Goiás, Regional Jataí, Curso de Licenciatura em Educação Física, 2011.

UFG. Projeto Político Pedagógico do Curso de Bacharelado em Educação Física. Jataí-GO: Universidade Federal de Goiás, Regional Jataí, Curso de Licenciatura em Educação Física, 2012.

VIANA, P. B.; BENINI, L. V.; VASCONCELlOS, C. Programa de ginástica laboral versus desconforto laboral. Coleção Pesquisa em Educação Física, Várzea Paulista - SP, v. 10, n. 2, p. 
125-132, 2011. Disponível em: <http://www.editorafontoura.com.br/periodico/vol-10/Vol10n22011/Vol10n2-2011-pag-125a132/Vol10n2-2011-pag-125a132.pdf>. Acesso em: 20 nov. 2015.

WERNECK, F. Z.; BARA FILHO, M. G.; RIBEIRO, L. C. S. Mecanismos de melhoria do humor após o exercício: revisitando a hipótese das endorfinas. Revista Brasileira de Ciência e Movimento, Brasília, v. 13, n. 2, p. 135-144, ago. 2005. Disponível em: <http://portalrevistas.ucb.br/index.php/RBCM/article/viewFile/634/645>. Acesso em: 25 jun. 2014.

Recebido em: 25.12 .2015

Aceito em: 31.10 .2016 